\title{
A FICÇÃO HIPERBÓlICA: APONTAMENTOS SOBRE O MÉTOdO DE INVESTIGAÇÃO FILOSÓFICA
} EM VILÉM FLUSSER

Hyperbolic fiction: some remarks on Vilém Flusser's method of philosophical investigation

Thiago Reis *

Resumo: Neste artigo procuraremos compreender o recurso ficcional em Flusser como método de investigação. A ficção em Flusser é utilizada não apenas como um laboratório imaginário de experimentações que por vezes auxiliam na paralaxe dos fenômenos, mas igualmente enquanto importante recurso retórico que, através da ficção hiperbólica "dá a ver" as transformações, por vezes imperceptíveis, que começam a irromper no horizonte das sociedades pós-industriais. Nos debruçaremos ainda sobre a fábula do Vampyroteuthis Infernalis, o que possibilitará não apenas analisar os meandros da produção filosófico-ficcional de Flusser, mas também introduzir temas referentes às transformações ocasionadas pela forma de existência pós-histórica.

Palavras-chave: Fiç̧ão. Fábula. Pós-história. Epistemologia. Vilém Flusser.

Abstract: This article aims to understand the way Flusser resorts to fiction as a method of philosophical investigation. For the author, fiction is not only used as an imaginary laboratory of experimentations, which sometimes support the parallax of phenomena, but also as an important rhetorical resource that, throu-

\footnotetext{
* Doutor em filosofia pela Universidade Federal de Minas Gerais (UFMG); Mestre em Estética e Filosofia da Arte pela Universidade Federal de Ouro Preto (UFOP). Docente do curso de Arquitetura e Urbanismo da Universidade de Uberaba. Artigo recebido em 14/12/2018 e aprovado para publicação em 28/05/2019.
} 
gh hyperbolic fiction, "reveals" transformations, sometimes imperceptible, that begin to emerge on the horizon of postindustrial societies. We also focus on the Vampyroteuthis Infernalis fable, to analyze the meanderings of Flusser's philosophical-fictional production, as well as introduce themes related to the transformations generated by the post-historical form of existence.

Keywords: Fiction. Fable. Post-history. Epistemology. Vilém Flusser.

querela entre o real e o ficcional parece não ter mais a sua razão
de ser. As ciências exatas, contradizendo desde há muito a visão de
Newton ("Hypotheses non fingo"), têm recorrido aos instrumentos ficcionais, como hipóteses e simulação de modelos, para conceber eventos possíveis ou de difícil observação, a exemplo da astronomia e de ciências que dependam de especulações de natureza teórica. ${ }^{1}$ Para além das questões epistemológicas, a narrativa científica também acaba por tangenciar o campo da ontologia, como é o caso dos modelos explicativos da física moderna, que povoam o universo com inúmeras partículas e subpartículas, as quais se encontram distantes de qualquer possibilidade perceptiva, mas que, ainda assim, nos servem enquanto "ficções úteis". Não se pode deixar de destacar os avanços no campo da cibernética, capazes de operar uma síntese dialética até pouco tempo impensada: o aparecimento da "realidade virtual". A filosofia, mesmo que por vezes tenha assumido ao longo de seu percurso uma posição reativa (ou mesmo ambígua) à ficção, serviu-se inúmeras vezes de narrativas ficcionais para a veiculação de conteúdos que procuravam abarcar de um modo não-sistemático uma variedade de temas que, eventualmente, apontassem para além do escopo teórico-argumentativo tradicional da disciplina. Em casos específicos, como a filosofia utópica do renascimento (Morus, Campanella, Bacon), a escolha da forma literária se apresenta como um terreno possível de experimentações conceituais - o que também é evidenciado em casos como o poema-filosófico de Nietzsche, no Zaratustra, ou na "filosofia de variedades", recorrente no início do século XX (Benjamin, Kracauer, E. Bloch). A literatura existencialista (Kierkegaard, Sartre e Camus), por sua vez, procurava aproximar as questões teóricas (como a fenomenologia e a ontologia) das relações cotidianas, contribuindo assim, de um modo relevante, para a popularização da filosofia, levando-a para além do âmbito do especialista.

No caso de Flusser, a apropriação da ficção não se dá enquanto um recurso eventual, mas constitui o cerne de seu desenvolvimento filosófico. Denominada por Abraham Moles como sendo Philosophiefiktion², o pensamento

\footnotetext{
${ }^{1}$ Bozzi chama a atenção para a etimologia da palavra ficção. Do latim fingere, ela designa "modelar, plasmar", e também, "fazer cópia similar à verdadeira", "simular". Cf. BOZZI, Vilém Flusser. Dal soggetto al progetto: libertà e cultura dei media, 2007, p. 64.

2 MOLES, "Philosophiefiktion bei Vilém Flusser", 1990, p. 53- 61.
} 
flusseriano intenta promover uma aproximação entre a filosofia e o mundo da vida, recorrentemente com o auxílio da ironia e da metáfora, e o faz ao mesmo tempo em que estabelece uma conexão entre distintos territórios do saber: filosofia, física, literatura, biologia, matemática, antropologia, cibernética etc. Num ensaio intitulado Da ficção (1966), o autor chegaria mesmo a afirmar que "a ficção é a única realidade", sob a premissa de que o mundo nada mais é do que a soma das interpolações entre as representações que dele são feitas, ou seja, um entrecruzamento de ficções. Ao tomar "uma mesa" como objeto-exemplo de análise, o autor promove uma paralaxe do olhar ao mostrá-la tanto enquanto uma realidade sólida (realidade dos sentidos), mas também como uma realidade oca, um campo eletromagnético (realidade das ciências exatas), além de fazer parte de um sistema complexo de significados (objeto fálico, artístico, industrial etc.). "Perguntar qual destes pontos de vista é mais verdadeiro", escreve Flusser, "carece de significado (...) afirmo a relatividade e equivalência de todos os pontos de vista possíveis". ${ }^{3}$ A ficção poderia ser assumida enquanto a falta de uma objetividade sólida, de uma realidade verdadeira, a falta de um ponto fixo e imutável no que concerne à nossa representação do mundo. Do ponto de vista genealógico, o filósofo praguense parece ter se servido do pensamento de Hans Vaihinger, autor da obra Philosophie des Als $\mathrm{Ob}$ [Filosofia do como se], na fundamentação de sua práxis ficcional. ${ }^{4}$ Segundo Guldin \& Bernardo,

Vaihinger afirma que todo discurso é ficcional, mesmo que pretenda não sê-lo. Todavia, todas as verdadeiras ficções, sejam da ciência, do direito, da filosofia ou da fiç̧ão stricto sensu, se caracterizam por serem internamente contraditórias. Tais contradições não devem ser negadas, mas sim exploradas, como se cada uma delas constituísse um labirinto rico de metáforas e alternativas para o pensamento. Na verdade, tudo o que dizemos e escrevemos é como se fosse verdade. A condição "como se" do discurso deve ser assumida sempre, sob pena de o pensamento esclerosar-se em dogma.

\footnotetext{
${ }^{3}$ FLUSSER, "Da Ficção", s/d.a

${ }^{4}$ Cabe observar ainda, que a teoria do "como se" privilegia sobretudo o estudo das "ficções científicas", associadas ao esforço imaginativo da ciência, ao possibilitar um manejo de "realidades" que não podemos dizer que "são" ou "não são". Desta feita, aproxima-se da posição dos antirrealistas que afirmam que algumas entidades (como as partículas subatômicas) são apenas "ficções úteis", as quais permitem prever observações, ao invés de serem reveladoras da natureza subjacente às coisas. As ficções úteis se encontram, deste modo, na espinha dorsal do debate entre realismo e antirrealismo - em outras palavras: na distinção entre observável e inobservável. Por exemplo: apesar de não observáveis, podemos utilizar o detector de partículas para "visualizar" o caminho percorrido por elétrons. Poderíamos afirmar então que os elétrons podem ser observados? O biólogo, ao utilizar um microscópio de alta potência estará detectando ou de fato observando algo diretamente? Nesse sentido, quando da utilização de aparatos para a "detecção" de fenômenos, diremos que estamos realmente observando um fato ou uma "realidade" gerada por aparelhos? Caso radicalizemos a posição antirrealista, da qual Flusser se aproxima, poderíamos arriscar que o aparelho é sobretudo, um gerador de ficções (sejam elas úteis ou não).
} 
Não posso dizer nunca "o que é", mas posso especular "como se fosse", responsabilizando-me palavra por palavra pela minha especulação, ou seja, pela minha ficção. ${ }^{5} 6$

A paralaxe epistêmica e ontológica do método-ficcional flusseriano serve ainda como um mote ou instrumento propício para o engendramento da dúvida - o que permitirá ao mesmo tempo a fundamentação de uma crítica epistemológica sui generis, quase sempre atrelada à crítica da cultura. Para Flusser, a dúvida não deve ser entendida como um meio para a obtenção de uma certeza definitiva e indubitável, mas um recurso reflexivo contínuo através do qual a dúvida deve inclusive duvidar de si mesma (a dúvida da dúvida). O filósofo faz, portanto, uma contraposição ao método cartesiano, uma vez que o propósito de Descartes, como se sabe, foi o de buscar um fim a todas as incertezas - "remover a terra movediça e a areia para encontrar a rocha"7 - e o faz a partir do momento em que toma a "dúvida" enquanto algo indubitável. Isso não quer dizer que Flusser partilhe de um ceticismo temerário. Antes, a seu ver, "a dúvida metodicamente aplicada produzirá, possivelmente, novas certezas, mais refinadas e sofisticadas" ainda que conservem "a marca da dúvida que lhes serviu de parteira". ${ }^{8}$

No entanto, apesar da diferença entre as metas estabelecidas pelos projetos filosóficos de Flusser e Descartes, ambos apelam a recursos ficcionais para a construção de seus argumentos. (Isso pode parecer, de início, como algo secundário, mas a nosso ver apontará para o núcleo da investigação filosófica flusseriana). O nosso intuito é o de ressaltar um traço distintivo presente nos dois filósofos, especificamente, de que maneira a retórica hiperbólica torna-se um elemento importante para a vinculação da dúvida, potencializando-a tanto do ponto de vista pedagógico, quanto no que concerne à eficácia retórico-argumentativa. Cabe ressaltar, a hipérbole é uma figura de linguagem que enfatiza o grau de percepção de determinado objeto, tanto por meio da diminuição ou, mais recorrente, do aumento de seus aspectos ou qualidades. Vejamos.

Nas Meditações, Descartes pretendia pôr em causa uma recusa de todas as opiniões até então presentes em seu espírito, primeiramente ao fazer um exame a respeito da confiabilidade do conhecimento sensível (erro dos sentidos e argumento dos sonhos) até culminar no argumento do "Malin Génie", momento em que a dúvida cartesiana será posta em grau hiperbólico. É importante notar, como aponta Paola Bozzi, que "a desvalorização

\footnotetext{
${ }^{5}$ BERNARDO, G. \& GULDIN, R. O homem sem chão: a biografia de Vilém Flusser, 2017, p. 120.

${ }^{6}$ Uma ressalva, entretanto, deve ser feita em relação à noção de entropia, que aparece recorrentemente nos escritos tardios de Flusser. Ela será sustentada de modo axiomático, constituindo, por assim dizer, um pano de fundo inexorável a respeito da realidade. Ou seja, a entropia não é uma ficção, mas um fato contra o qual todas as ficções orbitam.

${ }^{7}$ DESCARTES, Discours de la méthode, 2005, p. 56.

${ }^{8}$ FLUSSER, A Dúvida, p. 22.
} 
das representações mentais ditas 'só imaginação' (esta é uma expressão frequente no texto de Descartes) se dá ao mesmo tempo em que a ficção se torna um método de conjectura e é utilizada como argumento". ${ }^{9}$ Ao se servir da ficção do gênio maligno, a filosofia cartesiana pretendeu alcançar uma radicalização da dúvida, rejeitando todo e qualquer juízo sobre a realidade que não contivesse em si os mínimos traços de confiabilidade: "Vou supor, por consequência", dirá Descartes, "não o Deus sumamente bom, fonte da verdade, mas um certo gênio maligno, ao mesmo tempo extremamente poderoso e astuto, que pusesse toda sua indústria em me enganar", e continua: "Vou acreditar que o céu, o ar, a terra, as cores, as figuras, os sons, e todas as coisas exteriores não são mais que ilusões de sonhos com que ele arma ciladas à minha credulidade". ${ }^{10}$

Assim como em Descartes, o método crítico flusseriano também lançará mão da hipérbole através da ficção para a trama de argumentos. Ao dizermos ficção hiperbólica pretendemos demarcar uma postura retórica que "ao exagerar certos traços da realidade" procura criar "armadilha para nela captar um fenômeno qualquer (casa, Deus, político, forças da natureza)" ${ }^{11}$ É o caso exemplar do ensaio "O mito do cubo". Nesta "fábula inorgânica", o filósofo dá voz a um cubo de sal (!) com o intuito de explicitar os equívocos recorrentes da existência humana a partir do ponto de vista - ou do projeto existencial - "cúbico" do sal de cozinha. Ao espelhar as determinações ontológicas, éticas e estéticas do cubo de sal, e ao fazer do sal a medida de todas as coisas, o ensaio tem por finalidade apresentar uma caricatura de nossas próprias "mitofilias", revelando as incoerências presentes em nossas teorias acerca do mundo e de nós mesmos.

É próprio da caricatura exagerar certos traços da "realidade" a ser retratada e suprimir outros. Essa simplificação tem por finalidade ressaltar aquilo que o caricaturista considera mais característico, e servir, neste sentido restrito, de "explicação" da realidade. Essa "explicação" é válida na medida em que é como tal reconhecida pelos espectadores. ${ }^{12}$

Hamlet propôs a encenação de uma peça com a finalidade de alcançar a confissão do assassino de seu pai. Ao combinar com atores para que estes simulassem a morte do antigo rei, à espreita o protagonista esperava obter nos olhos do tio a comprovação do crime cometido - como de fato aconteceu. O que Hamlet propõe, tal como Flusser, é uma armadilha sob a forma da ficção. É neste sentido que pretendemos reafirmar a posição da ficção-filosófica em Flusser, como um fingir que tenta emboscar os fenômenos de nossa realidade. Ao fim e ao cabo, por meio de uma inversão, é a realidade, ela mesma, que deverá ser assumida enquanto uma trama

\footnotetext{
${ }^{9}$ BOZZI, 2007, p. 67.

${ }^{10}$ DESCARTES, Meditações sobre a filosofia primeira, 1992, p. I, § 12.

${ }^{11}$ FLUSSER, Parábolas, Hipérboles e Hiper-realismo, s/d.b

12 FLUSSER, Ficções Filosóficas, 1998, p. 33.
} 
repleta de ficções. Contudo, afirma Flusser, quem se finge de louco, como Hamlet, acaba por tornar-se também louco. Tal metáfora nos sugere que o clima de suspensão da crença e da dúvida, e a consequente "loucura do fingimento" que aí se instaura, traz consigo a perda de fundamentos ou, como prefere o filósofo: Bodenlosigkeit. Mas, de modo paradoxal, é por meio da ficção que será aberta a possibilidade de superação: a criação de platôs que assegurem novos caminhos transitáveis, rumo a uma realidade que a princípio surge enquanto um núcleo esvaziado, mas a partir do qual poderão ser projetados novos modelos de existência, permitindo realizar a realidade por meio de uma vida ficcional. Em Lingua e Realidade (1963), o filósofo já direcionava os seus esforços teóricos para defender a tese de que a "língua cria a realidade", e o faz ao avançar contra o indizível ou o nada que circunda os limites da própria realidade. ${ }^{13}$ Neste sentido, a língua é poietés, ou seja, tem a capacidade de produzir e estabelecer (poiein) o real. "A atividade poética é produtiva sensu stricto, arranca algo (es) das profundezas do inarticulado" - todavia, pergunta o filósofo, para logo em seguida responder: "de onde produz o poeta a língua? Ex nihilo, daquele nada indizível que é o Alfa e o Ômega da língua". ${ }^{14}$

Posteriormente, em O Universo das imagens técnicas (1985), obra que faz parte da fase tardia do autor, na qual são refletidos temas relacionados à teoria da comunicação e dos novos meios tecnológicos, Flusser ainda partilharia, mutatis mutandis, o mesmo ponto de vista que outrora, em sua fase brasileira, só que agora revestido com a luminosidade proveniente das imagens técnicas: é por meio destas que poderemos "adensar", sob a forma de camadas ou superfícies, a zerodimensionalidade, isto é, esse grau zero da realidade revelada pelo discurso técnico-científico (vide teoria quântica). Tal adensamento dependerá, por sua vez, da "imaginação" ou da ficção: "imaginar é fazer com que aparelhos munidos de teclas computem os elementos pontuais do universo para formarem imagens e, destarte, permitirem que vivamos e ajamos concretamente em mundo tornado impalpável $(\ldots)^{\prime \prime} .^{15}$ Mais uma vez: ficção hiperbólica. Só que neste caso específico, a partir de outra conotação. Não se trata do exagero enquanto traço retórico, que visa capturar ou apreender as variações fenomênicas para demonstrar de que modo o mundo é constituído através de um entrecruzamento de pontos de vista, mas hiperbólico no sentido de que a realidade, como um todo, deve ser considerada como um "meio imaginário", o que de certa maneira retoma a afirmação de que a "ficção é realidade", isto é, não mais na acepção de uma desconfiança, como se faz presente no ensaio Da ficção, e sim de que a ficção é o modo possível de preencher o nada da existência, seja frente ao caos do indizível ou à zerodimensionalidade irrealizada.

\footnotetext{
${ }^{13}$ Cf. FLUSSER, Lingua e Realidade, 1963, p. 141 e ss.

${ }^{14}$ FLUSSER, 1963, p. 162.

${ }^{15}$ FLUSSER, O universo das imagens técnicas, 2008, p. 43.
} 
Em resumo, e a nosso ver, o filósofo se servirá da ficção tanto como um recurso narrativo, o que lhe permitirá engendrar sugestivas reflexões conceituais, aos moldes de uma epistemologia fabulatória ou ciência de ficção (Vampyroteuthis Infernalis e O Universo das Imagens Técnicas), quanto recurso para a desconstrução e crítica do conhecimento e da cultura, geralmente efetuado por meio de um approach fenomenológico e a sua consequente variação de fenômenos (Natural:mente). Ao mesmo tempo, procuramos evidenciar uma especificidade argumentativa do filósofo que está atrelada ao seu método-ficcional, o qual pretende alguns sintomas de nossa realidade a partir de certo transbordamento retórico. Por fim, a ficção se apresenta enquanto saída à falta de fundamento (Bodenlosigkeit), tanto em relação ao caos irrealizado da existência quanto ao solo desfragmentado da existência pós-histórica.

É preciso ressaltar que ao desenredar os possíveis matizes do método-ficcional em Flusser não pretendemos de forma alguma esgotá-los. Antes, apenas demarcamos alguns aspectos que nos servirão de preâmbulo para explorar as particularidades relativas aos modos de investigação de Flusser. A partir de então, direcionaremos nossas reflexões para a compreensão da pós-história e os seus desdobramentos, e o faremos levando em conta a sua mais notória obra de ficção filosófica: Vampyroteuthis Infernalis. Por meio desta poderemos observar vários aspectos daquilo que constitui o mote da crítica flusseriana tardia, a qual procura estabelecer predições sobre as transformações pelas quais atualmente passa a sociedade humana rumo a uma nova forma de existência.

\section{De fabula narratur}

De Ésopo a La Fontaine e, mais recentemente com Orwell, a fábula sempre esteve presente na tradição literária do ocidente. ${ }^{16}$ Como se sabe, essa forma narrativa toma animais ou insetos como protagonistas que, além de resguardarem as características que lhes são próprias, espelham o comportamento humano aos moldes de um arranjo onde cada um de nós é retratado, com vistas geralmente à insurgência de uma sátira ou, o mais comum, de uma pedagogia moral. Flusser também irá se apropriar da fábula enquanto relevante recurso filosófico-ficcional. Contudo, apresentará

\footnotetext{
${ }^{16}$ Como sugere Ronald Williams, haveria indícios de que a gênese da tradição fabular, que habitualmente se atribui à Grécia antiga, tenha sofrido influências das "fábulas" mesopotâmicas (Acádia e Sumérios) ou, mais diretamente, das fábulas egípcias. Nesse sentido, mesmo diante da falta de elementos substanciais que permitam definir os contornos genéticos da fábula, não se pode deixar de considerar certa influência oriental na constituição deste gênero. (Cf. WILLIAMS, "The Literary History of a Mesopotamian Fable", 1955).
} 
ao mesmo tempo uma série de desvios em relação à fábula tradicional, principalmente no que diz respeito ao seu efeito pedagógico, instituindo o que poderíamos denominar de "fábulas amorais" - como nos esclarece em seu ensaio "Um mundo fabuloso", ao advertir que, diferentemente das fábulas lafontainianas, "a moral da história não será óbvia nem para o autor, nem para os que a ouvem", já que "a clareza das convicções morais pertence, infelizmente, ao passado" ${ }^{17}$ Chama-nos ainda a atenção não só o propósito "desvirtuado" da fábula, mas também as alterações quanto à escolha dos personagens - "os animais que falarão não serão nem mamutes nem raposas".$^{18} \mathrm{O}$ filósofo reúne em diálogo, certamente inusitado até mesmo em termos fabulosos, um octópode ("que habita os abismos dos oceanos"), uma solitária ("que habita os abismos dos intestinos") e um embrião humano ("que habita os abismos do útero), os quais lhe servem de mote para abordar algumas questões referentes à teoria da evolução, com retoques da teoria psicanalítica e da filosofia nietzschiana.

Em resumo, o octópode inicia o debate posicionando-se a favor da teoria darwiniana que, apesar de ter sido formulada por um "mero vertebrado", corrobora a sua superioridade evolutiva frente aos demais seres vivos. Nos oceanos, a vida pôde alcançar um maior grau de evolução, muito maiores se comparada com o ramo evolutivo que ocorreu acima da superfície: o seu poderoso cérebro central e a riqueza de seus órgãos sensoriais, defende $o$ octópode, seriam a prova disso. A solitária, por sua vez, ao assumir a sua superioridade na hierarquia evolutiva, ajunta Darwin, Freud e Nietzsche para defender que a força "que propele a evolução é a força libidinosa de procriação, a força da fertilidade", a "Vontade de Poder". Por conta de sua posição parasitária, ela consegue superar a "escravidão da alimentação e do movimento", uma vez que o corpo humano se torna meio para a satisfação de suas necessidades, contribuindo para que a sua vida seja desinibida, dedicada ao ato sexual ininterrupto. Já o embrião humano, que em comparação à solitária caracteriza-se pela inibição ou repressão, e em relação ao octópode seria marcado pela imperfeição evolutiva, defenderá que são as suas imperfeições que o tornam um ponto de inflexão para que a vida possa superar-se a si mesma.

Incontáveis barreiras se levantarão ao meu redor, para frustrar o meu caminho. A minha força vital, fraca e doente (como diz com razão o octópode), terá que se chocar contra essas barreiras. Serei um ser biologicamente mal adaptado. Mas nessa luta que terei que travar a força libidinosa que em mim opera será transformada. Por ser inibida, será sublimada. Nascerá em mim e por mim o amor, que tudo vence, inclusive a própria vida. ${ }^{19}$

\footnotetext{
${ }^{17}$ FLUSSER, 1998, p. 24.

${ }^{18}$ FLUSSER, 1998, p. 24.

${ }^{19}$ FLUSSER, 1998, p. 26.
} 
Como dito acima, essa fábula é "impermeável à moral", pois como nos revelam os discursos do octópode e da solitária, o mundo da vida se encontra "além do Bem e do Mal". É um "mundo diabólico", no qual o ser humano, abandonado em meio à crueza dos fatos, arrisca fazer a vida superar-se a si mesma por meio de frágeis princípios: o espírito e o amor. É importante ressaltar que, nessa fábula, o ser humano assume uma posição "anti-darwinista", ao reafirmar a sua posição não por ser, do ponto de vista hierárquico, o ápice da evolução, mas o contrário: "é por ser espécie menos adaptada que o homem é a meta da vida". ${ }^{20}$ A questão da evolução é tema recorrente nas ficções de Flusser, como mostra uma série de artigos, intitulada "Bichos", na qual o autor questiona a primazia humana geralmente assumida em relação ao percurso evolutivo dos entes biológicos. Segundo o filósofo, "todas as espécies, cada qual por si, representa um ponto máximo na evolução da vida". ${ }^{21}$ Não haveria, p. ex., nenhuma base objetiva para assumir uma suposta inferioridade das minhocas, as quais se mostram muito mais evoluídas do que nós no que se refere à regeneração de partes perdidas do corpo. Nota-se a evidente preocupação de Flusser em desconstruir o mito (ou a ficção) do progresso e da evolução. Isso porque a noção de evolução aliar-se-á por vezes, de forma deturpada, às noções de progresso e processo civilizatório, dando origem a teorias como o darwinismo social, servindo de sustentáculo não apenas para o culto do livre-mercado, mas também aos discursos raciais que objetivaram defender a superioridade de determinados povos, com vistas a alcançar, por meio de uma seleção artificial, a "pureza da raça".

Na obra Vampyroteuthis infernalis, o filósofo explicita a sua preocupação em rever o discurso da perspectiva otimista acerca do progresso para uma perspectiva mais sóbria do pós-Auschwitz e da era termonuclear. O filósofo assinalará de modo enfático a sua crítica às transformações ocorridas em nosso processo civilizatório, e que tende a ser catalisado com o assentamento da pós-história. Nos encontramos à beira do abismo, no limiar da escolha entre a barbárie e a possibilidade de emancipação. Publicada inicialmente na Alemanha, no ano de 1987, mas cujos manuscritos em português e alemão datam de 1981, a fábula sobre a lula-vampiro parece utilizar-se de ferramentas (pseudo-)analíticas próprias ao estudo da biologia, como a taxonomia, etologia e a teoria da evolução. De forma complementar, a obra é seguida por uma série de pranchas, aos moldes das ilustrações científicas, produzidas pelo artista e biólogo Louis Bec $^{22}$ para o também

\footnotetext{
${ }^{20}$ FLUSSER, 1998, p. 26.

${ }^{21}$ FLUSSER, "Bichos - I, II, III, IV e V", s/d.c.

${ }^{22}$ Bec certamente foi um interlocutor fundamental para a concretização da fábula sobre o octópode, não apenas por sua formação enquanto biólogo, mas por transitar pelas fronteiras da arte e da ciência, "buscando expandir o campo das ciências naturais como uma epistemologia fabulatória, baseada em formas de vida artificiais e segundo um método que chama de "tecnozoossemiótico". (Para mais sobre a relação entre Flusser e Bec, cf. BERNARDO \& GULDIN, O homem sem chão, 2017, p. 226 e ss.).
} 
fictício Institute Scientifique de Recherche Paranaturaliste. À medida em que a narrativa se desenvolve, contudo, torna-se evidente a construção de uma epistemologia fabulatória que, nas palavras do autor, pretende superar "a objetividade científica a serviço de um conhecimento concretamente humano". ${ }^{23}$ Trata-se ainda de um "experimento mental" (Gedankenexperiment) que permite ao filósofo a possibilidade de ultrapassar as barreiras que habitualmente cerceiam a imaginação científica, com vistas à obtenção de novas visões da realidade. Em uma de suas correspondências com a poeta Dora Ferreira, no momento em que redigia a obra, o filósofo relata alguns de seus propósitos: (i) obter uma visão distanciada ("objetiva") da condição humana, distância essa que não se constitui propriamente enquanto transcendência; (ii) escrever uma fábula que contenha ao mesmo tempo exatidão científica e fantasia louca: fantasia essata; por fim, (iii) contemplar a face do mal a partir do espírito da "transvaloração". ${ }^{24}$

Ainda que o Vampyroteuthis infernalis apresente as qualidades de uma fábula, é importante observar que ele tenderá a um deslocamento evidente no que respeita ao gênero, por não assumir um "diálogo" direto entre os personagens - como ocorre em "Um mundo fabuloso". Mostrará, todavia, uma transmutação ou uma quase-metamorfose. Somos convidados a experimentar uma transformação rumo a uma alteridade radical, tal como aquela experimentada pelo personagem Gregor Samsa. ${ }^{25}$ Como ressalta Bozzi, "o tratamento kafkiano da figura animal se diferencia daquela que conserva o gênero tradicional da fábula" uma vez que a besta "deve tornar-se modelo do comportamento humano" ${ }^{26}$, ao mesmo tempo em que o ser humano se torna modelo para o comportamento da figura animal. Através de uma dialética da transformação, evidencia-se certos pontos de instabilidade e uma desconstrução de nossa aparente constituição, intento capaz de nos jogar no âmago de nossa situação real frente aos desdobramentos do mundo. Por meio de "um jogo com espelhos deformadores", tal fábula assumirá os matizes de um estudo antropológico que paradoxalmente descentraliza a figura do próprio ser humano para constituir, a partir do outro que não sou - um molusco abissal - as transformações do próprio ser humano e fazê-lo consciente de sua condição histórica atual. Dos desdobramentos interpretativos possíveis, a fábula ainda induz a perscrutar questões próximas ao pós-humanismo, além de sinalizar aspectos relativos à organização da sociedade futura, em que as fronteiras entre a utopia e o totalitarismo tecnocrático tendem a se tornar cada vez mais tênues.

\footnotetext{
${ }^{23}$ FLUSSER, Vampyroteuthis Infernalis, 2011, p. 131.

${ }^{24}$ Correspondência com Dora Ferreira da Silva. Robion, 09/06/1981.

${ }^{25} \mathrm{Na}$ mesma correspondência supracitada, ressalta que tomou como modelos para a construção do octópode a Metamorfose (Kafka), Bosch e o Banquete, obra na qual Platão relata o mito de um ser perfeito, cuja forma é a de "uma esfera com oito braços".

${ }^{26}$ BOZZI, 2007, p. 74-75.
} 
Dentre todas as analogias propostas por Flusser entre os Vampyroteuthes e os seres humanos, destaque-se o fato de que ambas as espécies armazenam em memórias as informações adquiridas diante das experiências colhidas no mundo: produzem história. No caso dos seres humanos, os objetos se tornam os meios (ou media) apropriados para a transmissão e armazenamento de informações - de tal forma que a história da humanidade pode ser reconstruída pelo estudo dos objetos que compõem tal cultura. No caso do octópode, ele prescinde da mediação dos objetos para transmitir e armazenar informações. Para tanto, terá como suporte o seu próprio corpo (mediático), por meio dos cromatóforos que alteram a coloração da pele e do diverticulum, glândula que secreta nuvens de sépia - essa comunicação glandular serve, em outras palavras, para codificar informações e estabelecer comunicação intersubjetiva. A exemplo do diverticulum, que originariamente secretava sépia para confundir potenciais predadores, operando, portanto, como órgão de defesa, assumirá outra função no caso do Vampyroteuthis, nomeadamente cultural:

As nuvens por ele manipuladas vão assumindo formas das mais variadas, vão servindo de suporte a mensagens das mais variadas. $\mathrm{E}$ tais mensagens não mais são dirigidas a agressores, como em espécies mais primitivas, mas são dirigidas aos demais Vampyroteuthes. Trata-se, nas nuvens, de media da comunicação intersubjetiva. De media extremamente plásticos, efêmeros e fluidos, portanto rapidamente captáveis e de interpretação altamente duvidosa e conotativa. Mas uma coisa é certa: a função original do diverticulum é a de enganar o inimigo. É estratagema. Tal caráter enganoso, mentiroso, artificial, de artimanha, se conserva na função cultural que o diverticulum assume no Vampyroteuthis. As mensagens emitidas pelo Vampyroteuthis pelo medium da sépia são mentiras. ${ }^{27}$

No entanto, ainda que assumam função "cultural", as nuvens de sépia ou as tonalidades obtidas pelas transformações cromáticas da pele ainda resguardariam em si especificidades primitivas. No caso do uso dos chromatophora, sua função primitiva é claramente sexual: é utilizada para seduzir parceiros. Tardiamente assumem um papel "lírico", ao secretarem cores que revelam estados de interioridade: "trata-se de linguagem com sintaxe e léxico complexos" ${ }^{28}$ As nuvens de sépia, que antes eram utilizadas para enganar potenciais inimigos - isto é, eram modeladas de maneira a assumirem a forma mesma do Vampyroteuthis como um autorretrato, confundindo o agressor, que por sua vez atacava o simulacro ao invés do octópode real - posteriormente passam a configurar formas outras, variadas e extremamente plásticas, não mais dirigidas aos oponentes, mas aos pares do próprio octópode: tornam-se media de comunicação intersubjetiva. Ainda assim, tanto os chromatophora quanto as nuvens de sépia,

${ }^{27}$ FLUSSER, 2011, p. 90.

${ }^{28}$ FLUSSER, 2011, p. 89. 
guardam resquícios de suas funções arcaicas de engano e dissimulação. Isso instaurará uma permanente atmosfera conspiratória no interior da cultura vampyrotêuthica. Por meio de mensagens cifradas com intuito de seduzir e enganar o receptor, o octópode "usa media fluidos, efêmeros e altamente conotativos para que os seus parceiros não possam criticar as mensagens", e neste sentido, pretende que tais informações sejam assimiladas acriticamente pelos seus parceiros, o que transforma tal cultura "em conjunto de artifícios, de estratégias, de 'demagogias'" ${ }^{29} \mathrm{O}$ Vampyroteuthis conta ainda com uma glândula secretora de saliva, utilizada nos períodos arcaicos para paralisar potenciais vítimas, mas que com a evolução da espécie passa a cumprir a função de preparar os "objetos para serem processados com informações". ${ }^{30}$

A arte vampyrotêuthica encontrar-se-á intrinsecamente ligada às suas "glândulas comunicacionais". No caso da arte produzida pelos seres humanos, isso se dará através do interesse nos objetos - não sem dificuldade, posto que essa maneira de transmissão e armazenamento deverá enfrentar a perfídia dos mesmos, a exemplo da pedra que racha com a cinzelada do escultor. No caso do Vampyroteuthis, o seu interesse estará voltado exclusivamente para o outro, para transmissão e armazenamento informações diretamente na memória do outro. Contrapõe-se, deste modo, à nossa história da arte, que por longo tempo tem promovido o culto "estagnado" do objeto, esquecendo-se de seu propósito fundamental: "transmitir informações rumo a outros, a fim de que estes as armazenem". ${ }^{31}$ Cabe atentar que essa perspectiva é consonante ao projeto flusseriano de apontar aquilo que fundamenta a constituição mesma do mundo. $\mathrm{Ou}$ seja, para além de uma especulação que visa a relação ser humano/coisa, Flusser se voltará sobretudo pela relação eu-outro, ou seja, no processo de constituição de memórias e significados. A história da cultura resguarda em si um propósito que se vê obnubilado frente à cultura objetiva (qual seja, a intenção daquele que cria para se comunicar com o outro). Ora, ao se apoiar em tal perspectiva, para além de uma visão cujo objeto se torna o fetiche último na mediação das relações humanas, o filósofo reafirma que o mundo se constitui enquanto um campo de relações e, portanto, na intersubjetividade.

Após passar por determinada vivência, codificá-la para transmissão a partir de suas glândulas para seduzir, enganar e copular com seu semelhante - e nesse sentido, arte é sinônimo de artifício ou artimanha - a informação produzida pelo octópode será incorporada à memória de seus parceiros: é desta maneira que se estabelece a cultura dialógica vampyrotêuthica,

\footnotetext{
${ }^{29}$ FLUSSER, 2011, p. 91

${ }^{30}$ FLUSSER, 2011, p. 89.

${ }^{31}$ FLUSSER, 2011, p. 118.
} 
com a qualidade de ser um diálogo inexaurível, aere perennius, "tão eterno quanto o é a informação genética guardada no ovo". ${ }^{32} \mathrm{E}$ ao fazer arte, o Vampyroteuthis faz "teoria da comunicação". Aos poucos, contudo, vamos nos aproximando da arte comunicacional vampyrotêuthica:

As nossas estruturas comunicacionais vão se transformando fundamentalmente, no sentido de constituírem media efêmeros e transpassáveis, que permitem informar o outro sem ter que passar por objeto. É como se a humanidade, depois de uma volta multimilenar pelo mundo dos objetos, estivesse agora reencontrando o caminho do Vampyroteuthis. ${ }^{33}$

É preciso ressalvar que a arte vampyrotêuthica, ainda que contenha um caráter avançado em termos comunicológicos, funda-se inevitavelmente em sedução enganosa. O risco, aponta Flusser, é que essa é uma das possibilidades de nosso horizonte comunicacional. "Será a sociedade do futuro", indaga o filósofo, "necessariamente sociedade do ódio, da mentira, da violentação do outro por sedução e pelo engodo?" ${ }^{34}$ Como se sabe, os códigos transmitidos pela linguagem podem assumir tanto função conotativa quanto denotativa. No caso daqueles transmitidos pelo Vampyroteuthis, ainda que altamente conotativos, permitem uma única leitura - possuem, portanto, característica paradoxalmente denotativa por ocorrerem através de imposição estratégica, a exemplo do que ocorre em códigos publicitários. Ao enganar e seduzir seus parceiros por meio de ilusões, os Vampyroteuthes consumam a transmissão de informações. Esses são indícios "totalitários" da sociedade dos octópodes, igualmente perceptíveis nos meios de comunicação de massa da sociedade humana.

A sociedade vampyrotêuthica pode nos oferecer uma cartografia dos caminhos futuros a serem evitados pela humanidade. Ambos os modelos de sociedade compartilham, cada um a seu modo, o mesmo propósito, qual seja, o de superar a animalidade, romper os domínios da necessidade, rumo à liberdade. Para os seres humanos, tal superação ocorrerá por meio do engajamento na construção de uma sociedade que permita, ao mesmo tempo, igualdade e autoafirmação. No caso do Vampyroteuthis, uma vez que o núcleo da sociedade "é a comunidade de gêmeos nascidos do mesmo cacho de ovos" hierarquicamente programada, a liberdade se dará quando forem rompidos "os laços que os prendem aos gêmeos" tornando-os "desiguais uns aos outros". ${ }^{35}$ A política, para o Vampyroteuthis possui nuances "anarco-hobbesianas", uma luta de todos contra todos e a destruição de todas as estruturas pré-estabelecidas. Enquanto o propósito da nossa política é a constituição da pólis, para o

${ }^{32}$ FLUSSER, 2011, p. 119.

${ }^{33}$ FLUSSER, 2011, p. 119.

${ }^{34}$ FLUSSER, 2011, p. 122.

${ }^{35}$ FLUSSER, 2011, p. 103. 
octópode o engajamento passa pela destruição da mesma. A lembrança do propósito que nos propeliu à criação da cultura e da arte, pode nos ajudar a impedir os riscos que se encontram presentes na sociedade vampyrotêuthica. Como observa Flusser, na aurora da humanidade fomos obrigados a nos unirmos contra a ameaça originária do mundo dos objetos (natureza). O outro, ainda que por vezes tenha sido nosso adversário, foi e ainda é também um aliado que pode nos auxiliar a transformar e in-formar o mundo. Essa aliança primordial, todavia, vai caindo em esquecimento, em grande parte devido à cultura de massa: primeiramente, por dar ênfase aos objetos e ao seu consumo em detrimento do propósito informativo que os objetos deveriam resguardar. Em segundo lugar, porque tal cultura reifica os seres humanos, moldando-os aos propósitos individualistas e mercadológicos característicos da sociedade do consumo. Sociedade vampyrotêuthica.

Em seu poema "O Homem; As Viagens", Drummond fala das desventuras do ser humano em sua busca incansável, pelos vastos territórios do universo, de alguma plenitude, de algo que possa expurgar o fastio de viver. Contudo, profetiza o poeta, depois de colonizar os confins do universo, não restaria outra alternativa: deverá o ser humano fazer "a dificílima dangerosíssima viagem de si a si mesmo", para finalmente descobrir "em suas próprias inexploradas entranhas a perene, insuspeitada alegria de con-viver". De modo semelhante - mas certamente em tom menos otimista - ao final da obra dedicada ao Vampyroteuthis, após ter estabelecido inúmeras e intrincadas simetrias entre este e o ser humano, Flusser conclui: "este encontro de si próprio no outro extremo do mundo é o derradeiro propósito de todas as explorações humanas". ${ }^{36} \mathrm{O}$ propósito desta ficção nunca foi propriamente o estudo desse estranho habitante dos abismos, mas a profundidade dos oceanos da vida humana.

O mundo no qual vivemos tem a simetria dos espelhos contrapostos. Tudo em tal mundo se reflete. Tal simetria é consequência do estar-no-mundo humano. O homem se reflete no mundo, e o mundo, no homem, e este vai-vem de contraposições refletidas é a própria realidade humana. Pois isso implica não apenas que os abismos "externos" são reflexões dos abismos "internos" e vice-versa, mas implica igualmente que os abismos refletem o explorador e o explorador os abismos. ${ }^{37}$

"Je me sers d'animaux pour instruire les hommes". A máxima de La Fontaine ainda se mantém adequada aos propósitos da fábula de Flusser, ainda que, como indicado, com algumas ressalvas. Por meio de uma metáfora labiríntica, a intenção é a de nos fazer reconhecer esse outro em nós - a partir de nosso antípoda - e o filósofo, sem a proposição

\footnotetext{
${ }^{36}$ FLUSSER, 2011, p. 126.

${ }^{37}$ FLUSSER, 2011, p. 126.
} 
de um ensinamento moral, propõe-nos, antes, uma crítica do método: "quando se trata de pescar o Vampyroteuthis, é preciso que se pense de maneira fabulosa". Não se trata, contudo, de abandonar a ciência enquanto método de investigação, mas ajuntá-la ao que o filósofo denominou "ciência fictícia". O método científico pretende um conhecimento imparcial e objetivo, produz contos antifabulosos, justamente porque tende a negligenciar tudo aquilo que diz respeito à existência humana: nossos desejos, sonhos, angústias etc. Utilizando a biologia como uma armação da fábula, o intuito de Flusser era justamente o de "rechear tal esqueleto com a carne do sofrimento humano, os sucos dos desejos humanos e os nervos da sensibilidade e da inteligência humana". ${ }^{38}$ Deste modo, a fábula tornou evidente um método de análise que pode, quem sabe, "exorcizar" o Vampyroteuthis, trazendo-o vivo à superfície sem que, contudo, sejamos ameaçados por essa "despressurização". De outro modo, correremos os riscos de que a emergência do octópode irrompa de forma extremamente violenta.

Quando o Vampyroteuthis emerge, explode. Porque o Vampyroteuthis vive sob pressão, já que foi "recalcado" até o fundo, e quando sobe, a pressão relaxa e destrói a passagem. De maneira que o perigo parece não ser o próprio Vampyroteuthis, mas a pressão sobre ele exercida. Isto é a razão porque se tem acreditado longamente, e sobretudo durante o iluminismo, que bastaria descomprimir o Vampyroteuthis para torná-lo inócuo e "civilizado". (...) Infelizmente, a atualidade e o passado recente fornecem provas insofismáveis de que tal esperança é falha. ${ }^{39}$

Na Dialética do Esclarecimento, Adorno \& Horkheimer já haviam apontado para o fato de que a emergência do nazismo não fora um erro de percurso, mas a consequência do projeto de Esclarecimento, pretensamente emancipatório, e que foi gestado ao longo do processo civilizatório ocidental: "por que a humanidade", questionam os autores, "em vez de entrar em um estado verdadeiramente humano, está se afundando em uma nova espécie de barbárie" ${ }^{40}$. De modo sumário, o Esclarecimento sempre pautou o "desencantamento do mundo", transformando a razão em instrumento voltado para o domínio eficaz da natureza (tanto exterior e interior). $\mathrm{O}$ preço pago para "livrar os homens do medo e investi-los na posição de senhores" é o retorno da violência recalcada - perpetrada pelo racionalismo instrumental (ou, em termos flusserianos, da razão antifabulosa) para que houvesse a coesão social necessária na efetivação do domínio sobre a natureza - e que explode sob a forma do nazismo ou do antissemitismo. Flusser, em Pós-história (1983) seguirá as trilhas já indicadas pelos autores

${ }^{38}$ FLUSSER, 2011, p. 132

${ }^{39}$ FLUSSER, 2011, p. 127-128

${ }^{40}$ ADORNO \& HORKHEIMER, "O Conceito de Esclarecimento", In: Dialética do Esclarecimento, 2005, p. 11. 
da Escola de Frankfurt ao afirmar que Auschwitz é um acontecimento que já se encontrava virtualmente contido no programa de desenvolvimento da sociedade ocidental. Concordamos com Duarte sobre a possibilidade de interpretar o Vampyroteuthis Infernalis como uma "alegoria da pós-história nos seus aspectos gnosiológico, ético-político e estético". ${ }^{41}$ Das razões elencadas por Duarte que permitem vincular a fábula com a pós-história, podemos mencionar o fato de que a emergência do Vampyroteuthis, como apontamos logo acima, relaciona-se com o advento do nazismo (no primeiro instantâneo de Pós-história, Flusser caracterizará Auschwitz enquanto fenômeno que marca a emergência da pós-história). Outra forte razão é a paridade entre a comunicação glandular e "superficial" desenvolvida pelos octópodes com a cultura comunicativa pós-histórica promovida pelas tecnoimagens, em que a informação (imaterial) é sobrevalorizada em detrimento do suporte material.

Flusser pretende revelar, através de sua ficção, os espectros de um futuro que se avizinha com estranha familiaridade ${ }^{42}$. Isso porque a pós-história apresenta-se enquanto horizonte não totalmente efetivo, mesmo que o presente já contenha em si características que nos revelariam os indícios do surgimento da pós-história. É a partir desse interregno entre a história e a pós-história que podemos situar alguns dos escritos de Flusser, notadamente aqueles que apresentam traços utópicos, que expõem cogitações relativas ao futuro (e, portanto, de uma possibilidade ainda-não-realizada), mas que de algum modo parecem repercutir e servir de suporte à crítica de nosso tempo.

No início deste artigo havíamos chamado a atenção para a força argumentativa de Flusser, que procura capturar fenômenos muitas vezes imperceptíveis ou pouco aparentes, por se encontrarem ainda em forma germinal, in statu nascendi, mas que se encontram às vésperas de realização. A ficção hiperbólica, portanto, amplifica o futuro, "exageradamente", para que possamos perceber os indícios do porvir pós-histórico. Cabe ressaltar que Flusser, ao escrever o prefácio de Ins Universum der technischen Bilder, procura desvencilhar a sua teoria de uma "literatura fantástica futurista", revelando a sua crítica como "crítica do presente". Ao recorrermos à fabula do Vampyroteuthis, seguimos os passos de Flusser, que se serve do recurso narrativo como um eficaz instrumento para estabelecer certa empatia com o seu leitor. Deste modo, o futuro,

\footnotetext{
${ }^{41}$ DUARTE, 2012, p. 312.

${ }^{42}$ Remetemos aqui ao termo "unheimlich" (inquietante), expressão analisada por Freud e geralmente associada ao sentimento de intimidade ou familiaridade diante do estranho, que geralmente apresenta-se como algo assustador. Ao tentar revelar as ambiguidades que o termo carrega, o teórico vienense utiliza-se de várias definições, dentre as quais a proposta por Schelling, que define unheimlich como "tudo o que deveria permanecer oculto, mas apareceu". Cf, FREUD, 2010, p. 328-376.
} 
esse ainda-não, com todas as possibilidades a ele inerentes, apresenta-se ou passa a ser observado não como um ponto deslocado de nossa vivência mais imediata. A importância da fábula do Vampyroteuthis no corpus filosófico de Flusser é a de nos permitir, de modo preciso, observar um conjunto de preocupações que atravessam o seu pensamento - seja no tocante à crítica da racionalidade científica, à finitude e ao caráter projetivo da existência humana, à desmaterialização da cultura e ao papel da arte, da memória e da comunicação frente aos desafios da existência humana. Ao mergulharmos nas profundezas da escuridão abismal do Vampyroteuthis, assimilamos as categorias de uma existência semelhante àquela que se dará na escuridão da zerodimensionalidade, esse não-lugar de nossa existência futura.

\section{Referências}

ADORNO, T. \& HORKHEIMER, M. Dialética do esclarecimento: fragmentos filosóficos. Trad. Guido A. de Almeida. Rio de Janeiro: Zahar, 2005.

BERNARDO, G. \& GULDIN, R. O homem sem chão: a biografia de Vilém Flusser. São Paulo: Annablume, 2017.

BOZZI, P. Vilém Flusser. Dal soggetto al progetto: libertà e cultura dei media. Milano: UTET, 2007.

DESCARTES, R. Discours de la méthode. Texte et commentaire par E. Gilson. Paris: Librairie Philosophique, 2005.

DESCARTES, R. Meditações sobre a filosofia primeira. Trad. Gustavo Fraga. Coimbra: Livraria Almedina, 1992.

DUARTE, Pós-história de Vilém Flusser: gênese-autonomia-desdobramentos. São Paulo: Annablume, 2012.

FLUSSER,V. A dúvida. Rio de Janeiro: Relume Darumá, 1999.

FLUSSER,V. "Bichos - I, II, III, IV e V". (Manuscrito cedido pelo Arquivo Flusser Brasil). (s/d.c).

FLUSSER,V. "Da Ficção". (Manuscrito cedido pelo Arquivo Flusser Brasil). (s/d.a). FLUSSER,V. Ficções filosóficas. São Paulo: Editora da Universidade de São Paulo, 1998 FLUSSER,V. Ins Universum der technischen Bilder. Göttingen: European Photography, 1996.

FLUSSER,V. Língua e Realidade. São Paulo: Herder, 1963. 
FLUSSER,V. O universo das imagens técnicas. Elogio da superficialidade. São Paulo: Annablume, 2008.

FLUSSER,V. "Parábolas, Hipérboles e Hiper-realismo". (Manuscrito cedido pelo Arquivo Flusser Brasil). (s/d.b).

FLUSSER,V. Vampyroteuthis infernalis. São Paulo: Annablume, 2011.

FREUD, S. "O inquietante". trad. P. C. Souza. In: Freud, S., Obras Completas de Sigmund Freud, Vol. 14. São Paulo: Cia das Letras, 2010.

MOLES, A. "Philosophiefiktion bei Vilém Flusser". In: RAPSCH, V. (Org.). Überflusser: die Fest-schrift zum 70. von Vilém Flusser. Braunschweig: Stephan Bollmann Verlag, 1990, p. 53- 61.

WILLIAMS, R. "The Literary History of a Mesopotamian Fable" in: Phoenix (Toronto), v. 10, 1955, p. 70-77.

Endereço do Autor:

Rua Patrocínio, 139

Bairro Abadia

38025-480 Uberaba - MG

thiagoreis85@yahoo.com.br 